\title{
Experimental Hyperthermia during Cardiac Arrest and CPR Is Associated with Severe Spontaneous Hypothermia in Mice
}

\author{
Ruediger R. Noppens ${ }^{1,2}$, Julia Kofler ${ }^{2,3}$, Richard Traystman ${ }^{2,4}$ \\ ${ }^{1}$ Department of Anesthesiology, Medical Center of the Johannes Gutenberg University, Mainz, Germany; ${ }^{2}$ Department of Anesthesiology \\ and Peri-Operative Medicine, Oregon Health \& Science University, Portland, USA; ${ }^{3}$ Department of Pathology, University of Pittsburgh, \\ Pittsburgh, USA; ${ }^{4}$ University of Colorado Denver, Anschutz Medical Center, Colorado, USA. \\ Email: noppens@uni-mainz.de
}

Received June $1^{\text {st }}, 2012$; revised July $1^{\text {st }}$, 2012; accepted July $10^{\text {th }}, 2012$

\begin{abstract}
Background: Since genetically engineered mice are becoming more and more available, these animals become of high interest to study physiologic and pathophysiologic pathways of brain ischemia. The aim of this study was to examine body temperature $(\mathrm{Tb})$, physical activity variation and neurohistopathology in mice exposed to normothermic and hyperthermic cardiac arrest and cardiopulmonary resuscitation (CA/CPR). Methods: Male C57Bl/6 mice weighing 22 $27 \mathrm{~g}$ were implanted intraperitoneally with a radio telemeter and subjected to $10 \mathrm{~min}$ cardiac arrest followed by cardiopulmonary resuscitation. Normothermia $\left(37.5^{\circ} \mathrm{C}\right)$ or hyperthermia $\left(39.0^{\circ} \mathrm{C}\right)$ was induced by controlling peri-cranial temperature during the arrest period. Results: Hyperthermia during the arrest resulted in a Tb decrease during early recovery to a nadir of $28^{\circ} \mathrm{C} \pm 0.8^{\circ} \mathrm{C}$ (mean $\pm \mathrm{SE}$ ) and partially recovered to $34.4^{\circ} \mathrm{C} \pm 1^{\circ} \mathrm{C} 36 \mathrm{hrs}$ after CA/CPR. With normothermia during the arrest, $\mathrm{Tb}$ depression was less pronounced (nadir of $32.3^{\circ} \mathrm{C} \pm 0.3^{\circ} \mathrm{C}$ ) and recovered to physiologic levels within 24 hrs. Coupling of physical activity and body temperature was absent in all animals after CA/CPR. Neuronal injury in the caudoputamen was greater in the hyperthermia group. Conclusions: This study demonstrates that CA/CPR eliminates normal connectivity between body temperature and physical activity and induces long-lasting hypothermia, the depth of which is related to severity of brain injury. Long term temperature monitoring is required in survival murine experiments, if body temperature is a study variable.
\end{abstract}

Keywords: Cerebral Ischemia; Cardiac Arrest; Cardiopulmonary Resuscitation; Hypothermia; Neuroprotection; Telemetry; Hyperthermia

\section{Introduction}

It is now well recognized that body temperature strongly influences outcome from cerebral ischemia. The benefit of applied cooling in reducing neuronal damage and neurological deficits after stroke or cardiac arrest is evident in many animal injury models and in recent clinical trials $[1,2]$. Suppression of hyperthermia, should it develop spontaneously, is thought to improve brain histologic and neuro functional outcome after experimental and clinical focal cerebral ischemia $[3,4]$.

How body temperature is regulated throughout recovery in animal ischemic injury models is unclear and may be species, brain region and injury specific. For example, middle cerebral artery occlusion (MCAO) is associated with severe hyperthermia in rats (e.g. $39.5^{\circ} \mathrm{C}$ ) but causes hypothermia in mice (e.g. $33.1^{\circ} \mathrm{C}$ ) [5-7]. Global cerebral ischemia produces mild hyperthermia $\left(38.5^{\circ} \mathrm{C}\right)$ in gerbils but leads to hypothermia in rats $\left(34^{\circ} \mathrm{C}\right)$ and mice $\left(32^{\circ} \mathrm{C}\right)$
[8-10]. Although the effect of temperature on neuronal survival has been widely recognized and temperature is strictly controlled in animal models of brain injury, changes of body temperature after cardiac arrest and cardiopulmonary resuscitation (CA/CPR) in mice are not well described.

The aims of this study were 1) to characterize physiologic body temperature and physiologic activity in freely moving mice, 2) examine effects of normothermia and hyperthermia during global brain ischemia in a well established model of CA/CPR on body temperature and activity levels during 3-day recovery and 3 ) to evaluate neuronal injury in specific brain regions.

\section{Material and Methods}

\subsection{Animals}

Male C57Bl/6 mice (22 - 27 g, Charles River, Hollister, 
California) were treated according to NIH guidelines for the care and use of animals in research, and all experimental protocols were approved by the institutional animal care and use committee. All animals were housed in a temperature controlled room $\left(22^{\circ} \mathrm{C}\right)$ under a $12: 12$ hour dark:light cycle, room lights were turned on at 7:00 AM and turned off at 7:00 PM. Mice had free access to food (RMH 1000, 5P07, Purina Mills, USA) and water throughout the experiment. Surgical procedures were performed between 7:30 AM and 1:00 PM in all groups.

\subsection{Transient Global Brain Ischemia: Cardiac Arrest and CPR}

Cardiac arrest and CPR were performed as previously described [11,12]. Briefly, animals were anesthetized (halothane $1 \%$ - 3\% with supplemental oxygen), the trachea was intubated with a 20-gauge iv catheter and mice were mechanically ventilated (Mouse Ventilator MiniVent, Type 845, Hugo Sachs Electronic). Temperature probes were placed into the left temporal muscle and rectum, and a PE-10 catheter was inserted into the right jugular vein for drug administration. ECG was monitored using subcutaneous needle electrodes placed on the chest and a common ECG monitor (Hewlett Packard 78353B). Animals were allowed to stabilize for 15 minutes before induction of cardiac arrest. Peri-cranial temperature was controlled by attaching a circulating warm water coil around the head five minutes before cardiac arrest [11]. One minute before induction of cardiac arrest, body cooling was begun using an alcohol patch placed on the front side of the body and a water-filled pad placed underneath which was chilled by running through an ice-water bath.

CA was induced by intravenous injection of cold 0.5 $\mathrm{M} \mathrm{KCl} \mathrm{(50 \mu l)} \mathrm{via} \mathrm{the} \mathrm{jugular} \mathrm{catheter} \mathrm{and} \mathrm{confirmed} \mathrm{by}$ the presence of isoelectric ECG. Anaesthesia and ventilation were discontinued, and the endotracheal tube was disconnected from the ventilator. Body temperature was allowed to fall during the arrest to $27^{\circ} \mathrm{C}$, then the cooling devices were removed.

CPR was initiated at 10 minutes of CA by i.v.injection of pre-warmed epinephrine $(0.3 \mu \mathrm{g} / \mathrm{kg}$ in $0.5 \mathrm{ml}$ saline), chest compressions (approximately 300/min) and ventilation with $100 \%$ oxygen. CPR was concluded once ECG and cardiac contractions confirmed restoration of spontaneous circulation (ROSC). Resuscitation efforts were ceased, and the animal excluded from the study if ROSC was not achieved by 2.5 minutes of CPR. The circulating water coil was removed and the body temperature was raised to physiologic levels $\left(37^{\circ} \mathrm{C}\right)$ in a controlled manner using an electrical warming pad. A radiotelemeter $(22 \times 8 \mathrm{~mm})$ was inserted under aseptic conditions into the peritoneal cavity for measurement of body temperature $(\mathrm{Tb})$ and spontaneous physical activity (Activity;
Vital View ER-4000, Mini Mitter, USA) 10 min after ROSC as previously described and adapted for mice [13]. All probes were cleaned with $70 \%$ alcohol and rinsed with normal saline prior to ethylene oxide gas sterilization before use in animals. Each mouse was singly housed on an ER 4000 receiver platform and computer system for data recording. Tb and Activity were sampled once a minute (VitalView ${ }^{\circledR}$ software, Mini Mitter, USA). Activity is measured as a relative count by determining gross motor activity on the receiver platform. This method does not allow measurement of e.g. a distance traveled or the moving speed of the mouse.

After 30 minutes, mice were disconnected from the ventilator and breathing effort and pattern was evaluated. When a normal respiratory rate $(120 / \mathrm{min})$ with sufficient strength of the breathing musculature was present, the endotracheal tube and catheter were removed and skin wounds closed. The animal was returned to its homecage 35 minutes after CA/CPR for continuous monitoring of $\mathrm{Tb}$ and Activity for the following 3 days. Animals not surviving the 3-day period were excluded from the study.

\subsection{Experimental Groups}

\subsubsection{Experiment 1: Measurement of Physiological Body Temperature Variation and Physical Activity}

We first assessed the physiological pattern of body core temperature and activity variation in healthy mice. Nine animals were examined in this experiment. A radiotelemeter was implanted and animals were allowed to recover 1 week with full access to food and water before recording of $\mathrm{Tb}$ and Activity for 3-days.

\subsubsection{Experiment 2: Effect of Normothermia or Hyperthermia during Brain Ischemia on Body Temperature Variation, Physical Activity, Mortality and Neuronal Survival}

To evaluate if $\mathrm{Tb}$ and Activity during recovery from $\mathrm{CA} / \mathrm{CPR}$ was altered by the level of brain injury, a total of 26 mice were randomized to receive either normothermia (peri-cranial temperature during cardiac arrest: $37.5^{\circ} \mathrm{C}, \mathrm{n}=8$ ), hyperthermia (peri-cranial temperature $39^{\circ} \mathrm{C}, \mathrm{n}=11$ ) or sham surgery ( $\mathrm{n}=7$, animals followed the normothermia experimental protocol except receiving $\mathrm{CA} / \mathrm{CPR}$ ). Radio-telemetric monitoring was performed for 3-days after CA/CPR.

\subsection{Histology}

At 3 days post-arrest, mice were deeply anesthetized with halothane and the brain was perfusion-fixed (10\% phosphate buffered formalin, as previously described [11]. Tissue analysis was performed by standard hematoxylin 
and eosin histology. For analysis, viable and non-viable neurons were counted by an investigator blinded to treatment regimen using light microscopy $(100 \times)$ in the CA1 region of hippocampus (bregma $-1.5 \mathrm{~mm}$ ), and rostral and caudal caudoputamen (bregma 0.5 and $-1 \mathrm{~mm}$, respectively). The entire length of the CA1 sector was counted, and six microscopic fields were evaluated following a distinctive pattern in both levels of the caudoputamen. Non-viable neurons were identified by pink hypereosinophilic cytoplasm and a dark pyknotic nucleus, and the percentage of neurons that were non-viable was calculated for each region of interest.

\subsection{Statistical Analysis}

All data are expressed as mean \pm SE. Comparison of treatment groups for physiologic variables and neurohistopathology were performed using one-way analysis of variance (ANOVA) and post-hoc Tukey test or t-Test where applicable (Sigma Stat 3.0, SPSS Inc.). A one-way repeated measures analysis of variance and post-hoc test (Dunnett's Method) was used for analysis of body temperature in each group. Fisher's Exact Test was used for animal survival analysis. Differences were considered statistically significant with $\mathrm{p}<0.05$.

\section{Results}

\subsection{Tb and Activity in Healthy Mice (Experiment 1)}

We observed that higher body temperatures and activity levels occurred during the dark vs light cycle, indicating strong circadian rhythm variation (Figure 1). Tb and activity were highest shortly after light changes in the housing room. Tb and activity appeared coupled in periods of high spontaneous activity and correlated well with increased body temperature $\left(r^{2}=0.67\right)$.

\subsection{Physiologic Parameters (Experiment 2)}

Body weight at the day of surgery, CPR time and epinephrine dose were not different between groups (Table 1). All mice were successfully resuscitated after CA/CPR. As intended, peri-cranial temperature during injury was higher in normothermia vs hyperthermia groups ( $\mathrm{p}<$ 0.001 ), however temperature was equivalent in both injury groups by 30 minutes post-arrest (Table 2). Mortality was not statistically different between normothermia and hyperthermia groups ( $\mathrm{p}=0.49$, Table 1$)$.

\subsection{Body Temperature and Activity after CA/CPR (Experiment 2)}

$\mathrm{Tb}$ and Activity decreased spontaneously during recovery from $\mathrm{CA} / \mathrm{CPR}$, and this effect was most striking in

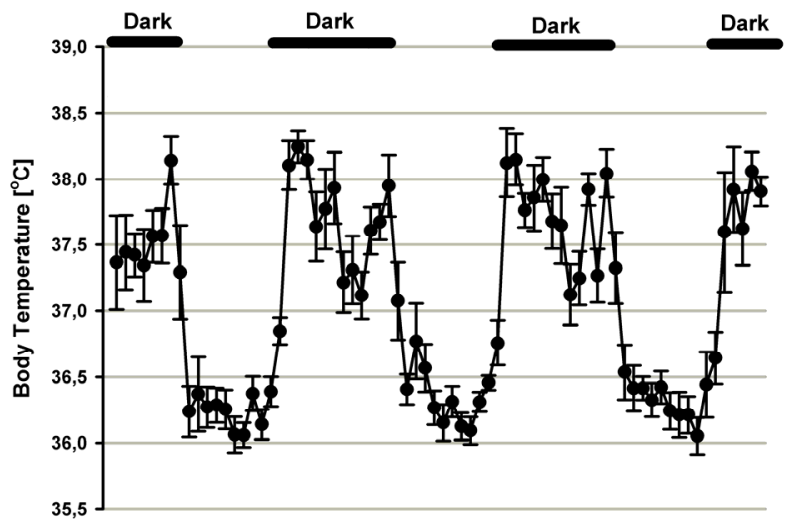

(a)

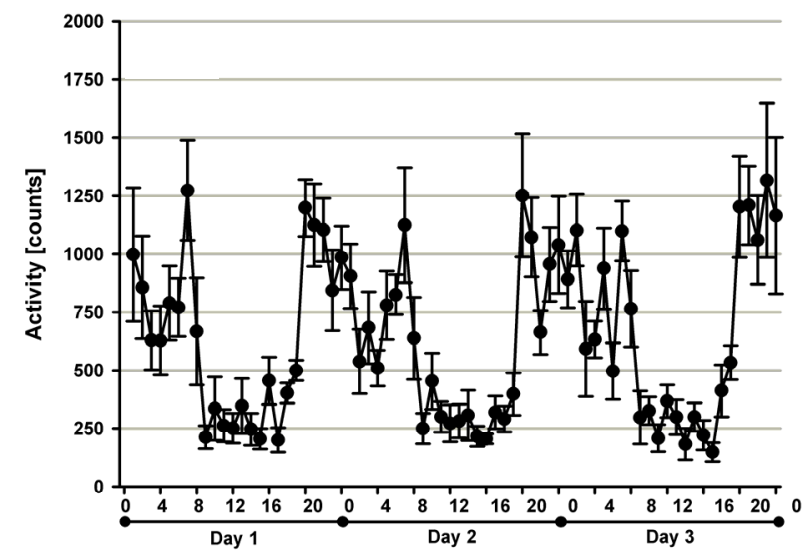

(b)

Figure 1. Physiologic body-temperature (a) and activity (b) in healthy male C57Bl/6 mice. 12:12 hour light:dark cycle (7 AM:7 PM) is marked as black bars; $n=9$, mean \pm SE.

Table 1. Body weight, CPR duration, Epinephrine dose and Animal survival.

\begin{tabular}{|c|c|c|c|}
\hline & \multicolumn{3}{|c|}{ Experimental Group } \\
\hline & Sham & Normothermia & Hyperthermia \\
\hline Body Weight [g] & $24.8 \pm 0.6$ & $24.6 \pm 0.5$ & $25.8 \pm 0.7$ \\
\hline CPR Duration [sec] & & $59 \pm 8$ & $61 \pm 8$ \\
\hline Epinephrine $[\mu \mathrm{g}]$ & & $7 \pm 0.4$ & $9 \pm 0.7$ \\
\hline Epinephrine[$[\mu \mathrm{g} / \mathrm{g} / \mathrm{BW}]$ & & $0.3 \pm 0.02$ & $0.3 \pm 0.02$ \\
\hline Animal Survival & $\begin{array}{c}7 / 7 \\
(100 \%)\end{array}$ & $\begin{array}{c}8 / 8 \\
(100 \%)\end{array}$ & $\begin{array}{c}9 / 11 \\
(82 \%)\end{array}$ \\
\hline
\end{tabular}

Normothermia: $37.5^{\circ} \mathrm{C}$ during CA/CPR; Hyperthermia: $39^{\circ} \mathrm{C}$ during CA/ CPR. Mean \pm SE.

the hyperthermia group (Figure 2(a)). Tb fell during early recovery in the hyperthermia group and reached a nadir of $28^{\circ} \mathrm{C} \pm 0.8^{\circ} \mathrm{C}(\mathrm{p}<0.001$ as compared to baseline values). Tb partially recovered to $34.4^{\circ} \mathrm{C} \pm 1^{\circ} \mathrm{C}$ at $34 \mathrm{hrs}$ post CA ( $<<0.001$ as compared to baseline values), then 
again decreased. Phases of high activity levels were not accompanied by a significant increase of Tb. Although $\mathrm{Tb}$ remained low at all times, spontaneous activity was evident by 8 hours, increased steadily then again declined 40 hours after CA/CPR (Figure 2(b)). A physiologic activity variation, as observed in sham operated animals, was absent during the observation period. In the normothermia group, Tb was also depressed for hours after CA/CPR, but the nadir for Tb depression was less $\left(32.3^{\circ} \mathrm{C} \pm 0.3^{\circ} \mathrm{C}\right)$, and full recovery of $\mathrm{Tb}$ did occur. During the first 12 hours activity was higher than in the other groups, followed by a decrease in the following observation period. Nevertheless, the normal coupling of $\mathrm{Tb}$ and spontaneous activity was lost and physiologic variation was absent in the normothermia group. Despite high spontaneous activity during the first post-arrest day, $\mathrm{Tb}$ remained low $\left(32.8^{\circ} \mathrm{C} \pm 0.5^{\circ} \mathrm{C}\right.$ at 10 hours $)$.

\subsection{Neurohistopathological Injury (Experiment 2)}

Neuronal injury was similar in the hippocampal CA1 region in normothermia and hyperthermia groups (Figure 3). Mice subjected to hyperthermic cardiac arrest had a higher percentage of injured neurons at the caudal and rostral level of the caudoputamen than normothermic cardiac arrest mice ( $<<0.001$ and $\mathrm{p}<0.05$, respectively). Injury was greater in both groups at the caudal caudoputamen than at the more rostral level.

\section{Discussion}

This study demonstrates that mice undergoing hyper-

Table 2. Body temperature and Peri-Cranial Temperature at Baseline, end of Cardiac Arrest period, and $\mathbf{1 0}$ and $\mathbf{3 0}$ min after Restoration of Spontaneous Circulation (ROSC).

\begin{tabular}{|c|c|c|c|}
\hline & \multicolumn{3}{|c|}{ Experimental Group } \\
\hline & Sham & Normothermia & Hyperthermia \\
\hline \multicolumn{4}{|c|}{ Rectal Temperature $\left({ }^{\circ} \mathrm{C}\right)$} \\
\hline Baseline & $36.8 \pm 0.1$ & $36.5 \pm 0.1$ & $36.6 \pm 0.1$ \\
\hline $\begin{array}{l}10 \text { min Cardiac } \\
\text { Arrest }\end{array}$ & $33.4 \pm 0.1$ & $27.3 \pm 0.2$ & $26.8 \pm 0.3$ \\
\hline 10 min ROSC & $34.8 \pm 0.1$ & $30.6 \pm 0.4$ & $29.5 \pm 0.5$ \\
\hline 30 min ROSC & $36.8 \pm 0.1$ & $37.2 \pm 0.2$ & $36.6 \pm 0.3$ \\
\hline \multicolumn{4}{|c|}{ Peri-Cranial Temperature $\left({ }^{\circ} \mathrm{C}\right)$} \\
\hline Baseline & $34.7 \pm 0.3$ & $34.6 \pm 0.2$ & $34.5 \pm 0.2$ \\
\hline $\begin{array}{c}10 \text { min Cardiac } \\
\text { Arrest }\end{array}$ & $37.5 \pm 0$ & $37.5 \pm 0^{* * *}$ & $39 \pm 0.1$ \\
\hline 10 min ROSC & $35.6 \pm 0.1$ & $31 \pm 0.1$ & $31.2 \pm 0.4$ \\
\hline 30 min ROSC & $34.6 \pm 0.2$ & $34.8 \pm 0.1$ & $34.7 \pm 0.1$ \\
\hline
\end{tabular}

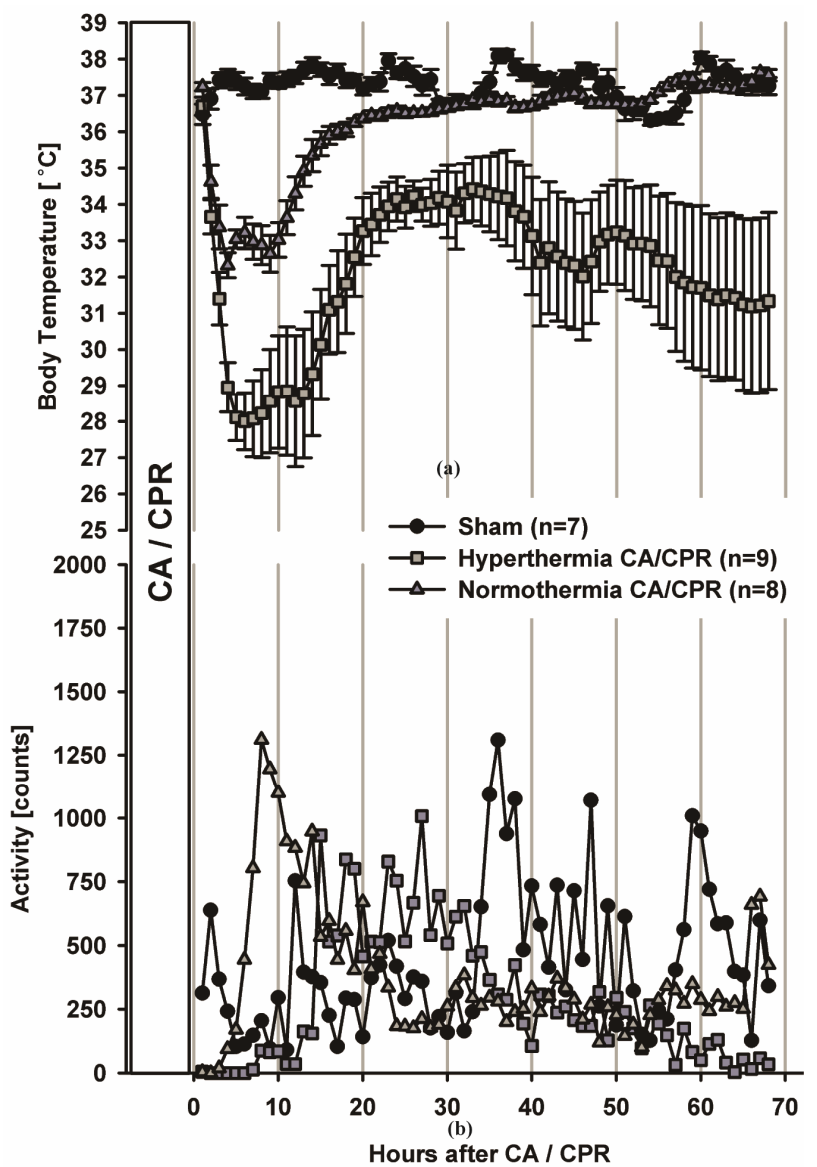

Figure 2. Body core temperature (a) and Activity (b) in the housing cage after cardiac arrest and CPR. BI: Brain Injury; Mean \pm SE.

thermia during CA/CPR have loss of post-ischemic temperature regulation, spontaneous severe hypothermia as well as uncoupling of spontaneous activity and body temperature. Normothermia during brain injury resulted in a milder form of spontaneous hypothermia and a loss of circadian temperature regulation. Hyperthermia during CA/CPR resulted in greater neuronal injury in caudoputamen, suggesting that spontaneous marked hypothermia during recovery is related to the severity of brain injury. A corollary of the present observations is that long term temperature monitoring is required in survival murine experiments, if body temperature is to be controlled as a study variable.

We observed that body temperature and physical activity varied in a circadian rhythm under basal conditions, a phenomenon that has been described in mice and which differs amongst mouse strains commonly used as experimental models in neuroscience [14,15]. In mouse, physiologic temperature ranges from mild hypothermia during periods of low activity to hyperthermia during high activity. However, circadian fluctuations are imme 


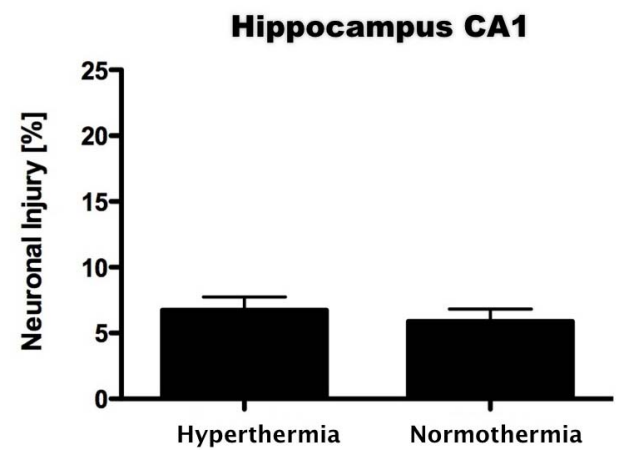

(a)

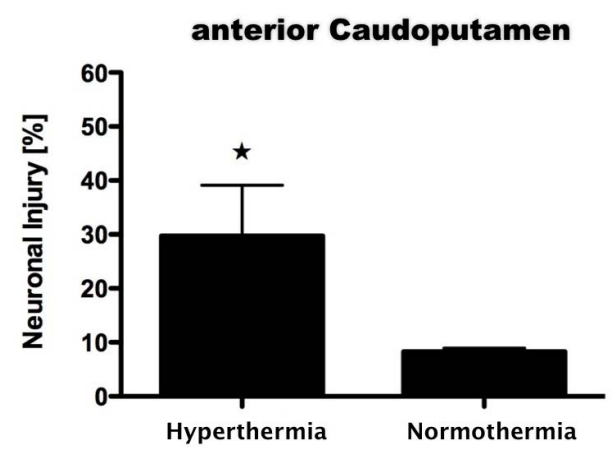

(b)

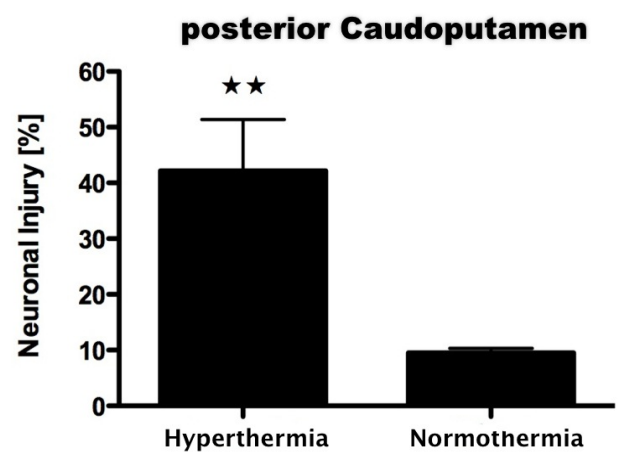

(c)

Figure 3. Neuronal injury after cardiac arrest and CPR. A: CA 1 field of the hippocampus; B: rostral caudoputamen; C: caudal caudoputamen. ${ }^{*} \mathrm{p}<0.05,{ }^{* *} \mathrm{p}<0.01$. Mean $\pm \mathrm{SE}$.

diately ablated, and not restored, in animals that sustain injury from global cerebral ischemia. In murine models of focal ischemia, hyperactivity has been described previously and its level has been associated with severity of brain injury $[16,17]$.

The depth of spontaneous hypothermia induced by $\mathrm{CA} / \mathrm{CPR}$, even in the presence of persistent physical activity, is surprising. Spontaneous hypothermia after CA/CPR has been described in a rat model of asphyxial cardiac arrest, with recovery to control values by $36 \mathrm{hr}$ ROSC [8]. In another study, rats developed moderate hypothermia $\left(32^{\circ} \mathrm{C}\right)$ five hours after $\mathrm{CA} / \mathrm{CPR}$ and recovered within eight hours to normal body temperature [18].
The depth of hypothermia was less in these studies, and recovery more rapid, than we observed in our mouse model of CA/CPR. Other rat models of brain ischemia have also been associated with spontaneous temperature changes during recovery. The four-vessel occlusion model in rat causes mild hypothermia in brain [19]. However, results are inconsistent in studies examining temperature changes in the two-vessel occlusion model of brain ischemia. One study reports a period of hyperthermia lasting up to three days and a loss of circadian temperature variation after the insult [20]. In a later study using the same model of brain ischemia, no postischemic temperature changes could be demonstrated [21]. In a modified model of two-vessel occlusion, a brief two hour period of mild hypothermia was followed by recovery to normothermia within six hours after the insult [22]. In a model of two vessel occlusion in C57Bl/6 mice, spontaneous hypothermia occurred after the insult[10]. In agreement with our results in the normothermia during CA/CPR group, the lowest body temperature in this study was $32^{\circ} \mathrm{C}$ and recovered to physiologic levels within 24 hours after brain ischemia [10]. Spontaneous hypothermia in patients, especially in pediatric patients has also been reported anecdotically, however this finding has not been systematically evaluated [23]. In part, the lack of attention to endogenous temperature dysregulation is due to ongoing interest in therapeutic cooling after CA/CPR or traumatic brain injury. Mild to moderate hypothermia post arrest remains to date the only successful neuroprotective strategy applied to humans and is used increasingly in intensive care units for selected patients [1,2]. In contrast, post-injury hyperthermia worsens outcome and increases neuronal injury [24,25].

The hyperthermia during CA/CPR group in our study exhibited severe hypothermia in the first hours of recovery, with only incomplete recovery during the 3-day observation period. The mechanism for initiation/maintenance of spontaneous hypothermia is not clear. However, it is unlikely that low physical activity was responsible for low temperature in this set of experiments. Mice exhibited high activity levels in the first 12 hours post arrest, yet body temperature failed to rise to basal levels. Normothermia during CA/CPR mice also showed early hyperactivity at periods when their lowest temperatures were observed. The hyperthermia during CA/CPR group presented body temperatures during early recovery similar to body temperatures that have been described in torpor. Topor is a temporary hibernation-like state that has been previously shown during times of food restriction $[14,26]$. In contrast to topor, which is characterized by a state of motor inactivity, animals in this study showed a high level of activity in the early phase of recovery without a corresponding increase of body temperature. 
A limitation of our study is that hyperthermia during CA/CPR was used to induce more severe brain injury. The temperature manipulations in our model may have contributed to post-arrest temperature dysregulation. However, a milder form of spontaneous hypothermia, albeit in a milder form, has also been described in other mouse models of global ischemia without intra-ischemic hyperthermia [10]. Therefore, we believe that the temperature dysregulation in our model is a direct result of increased neuronal injury and only indirectly related to the experimental temperature manipulation. We did not specifically monitor weight changes or food and water intake in our animals. However, we noted that most mice in the hyperthermia group did not appear healthy at the end of the 3-day observation period. Some of these animals might not have survived much longer than four days after cardiac arrest and CPR. Several reasons for the poor health of these animals exist, e.g. multi organ failure, which might have been responsible for body temperature and decreased activity two to three days after the insult, but is unlikely responsible for the $\mathrm{Tb}$ and activity alterations during the early recovery period.

The present study does not determine the potentially complex mechanisms underlying spontaneous postischemic hypothermia. However, the data underscore the need for long term monitoring of body temperature in mouse brain injury models and emphasize the extreme change that occurs in temperature regulation. It is well recognized that temperature in recovering animals is influenced by multiple factors, including method of temperature measurement, anesthetic regimen and injury model $[6,8,27,28]$. Furthermore, the neuroprotective potential of a number of pharmacologic agents such as MK-801, NBQX or Magnesium has been linked to temperature [29-31]. Therefore, interactions with brain injury induced spontaneous hypothermia and investigational neuroprotective drugs must be considered.

No guidelines exist on how body or brain temperature in small rodents after brain ischemia should be measured or controlled. Several techniques have been published, including the use of heating devices such as infrared lamps or the use of incubators used in human medicine $[8,32]$. In a recent review, MacLellan et al recommended tight temperature measurements of the brain and body during surgery as well as during recovery after brain ischemia for at least one day [33]. Telemetry probes are strongly recommended for measuring temperature in conscious rodents because this technique allows repeated measurements without stressing the animal by handling as is necessary with rectal measurements. It is also important that the use of a temperature controlled environment does not obviate the need for frequent temperature measurements since experimental animals could present with either hyper- or hypothermia after brain ischemia. Heating as well as cooling devices must be positioned in such a way that animals are exposed uniformly. The use of infrared lamps is discouraged as they impose a risk of non-uniform heating and overheating of an impaired post-ischemic animal.

In conclusion, the present results demonstrate severe spontaneous hypothermia after CA/CPR in mice, which is partially spontaneously reversible. However, future studies will be necessary to determine which mechanisms are involved. Our results also underline the necessity for monitoring body temperature in survival murine studies since temperature is a major factor influencing outcome.

\section{Acknowledgements}

This study was supported by National Institutes of Health, grants NS 46072, NS 20020 and NS 33368. None of the authors has a financial interest to disclose.

Experiments were conducted at Oregon Health \& Science University, Department of Anesthesiology and PeriOperative Medicine, Portland, Oregon, USA.

\section{REFERENCES}

[1] S. A. Bernard and M. Buist, "Induced Hypothermia in Critical Care Medicine: A Review," Critical Care Medicine, Vol. 31, No. 7, 2003, pp. 2041-2051. doi:10.1097/01.CCM.0000069731.18472.61

[2] L. J. Morrison, C. D. Deakin, P. T. Morley, et al., "Part 8: Advanced Life Support: 2010 International Consensus on Cardiopulmonary Resuscitation and Emergency Cardiovascular Care Science with Treatment Recommendations," Circulation, Vol. 122, No. 16, 2010, pp. S345-S421. doi:10.1161/CIRCULATIONAHA.110.971051

[3] M. D. Ginsberg and R. Busto, "Combating Hyperthermia in Acute Stroke: A Significant Clinical Concern,” Stroke, Vol. 29, No. 2, 1998, pp. 529-534. doi:10.1161/01.STR.29.2.529

[4] D. W. Marion, "Controlled Normothermia in Neurologic Intensive Care,” Critical Care Medicine, Vol. 32, No. 2, 2004, pp. S43-S45. doi:10.1097/01.CCM.0000110731.69637.16

[5] P. A. Barber, L. Hoyte, F. Colbourne and A. M. Buchan, "Temperature-Regulated Model of Focal Ischemia in the Mouse: A Study with Histopathological and Behavioral Outcomes,” Stroke, Vol. 35, No. 7, 2004, pp. 1720-1725. doi:10.1161/01.STR.0000129653.22241.d7

[6] F. Li, T. Omae and M. Fisher, "Spontaneous Hyperthermia and Its Mechanism in the Intraluminal Suture Middle Cerebral Artery Occlusion Model of Rats,” Stroke, Vol. 30, No. 11, 1999, pp. 2464-2471. doi:10.1161/01.STR.30.11.2464

[7] Q. Zhao, H. Memezawa, M.-L. Smith and B. K. Siesjö, "Hyperthermia Complicates Middle Cerebral Artery Occlusion Induced by an Intraluminal Filament,” Brain Re- 
search, Vol. 649, No. 1-2, 1994, pp. 253-259. doi:10.1016/0006-8993(94)91071-5

[8] R. W. Hickey, H. Ferimer, H. L. Alexander, et al., "Delayed, Spontaneous Hypothermia Reduces Neuronal Damage after Asphyxial Cardiac Arrest in Rats," Critical Care Medicine, Vol. 28, No. 10, 2000, pp. 3511-3516. doi:10.1097/00003246-200010000-00027

[9] W. C. Plahta, D. L. Clark and F. Colbourne, “17 $\beta$-Estradiol Pretreatment Reduces Ca1 Sector Cell Death and the Spontaneous Hyperthermia That Follows Forebrain Ischemia in the Gerbil," Neuroscience, Vol. 129, No. 1, 2004, pp. 187-193. doi:10.1016/j.neuroscience.2004.07.037

[10] G. Wei and S. Doré, "Importance of Normothermia Control in Investigating Delayed Neuronal Injury in a Mouse Global Ischemia Model," Journal of Neuroscience Methods, Vol. 185, No. 2, 2010, pp. 230-235. doi:10.1016/j.jneumeth.2009.09.026

[11] J. Kofler, K. Hattori, M. Sawada, et al., "Histopathological and Behavioral Characterization of a Novel Model of Cardiac Arrest and Cardiopulmonary Resuscitation in Mice,” Journal of Neuroscience Methods, Vol. 136, No. 1, 2004, pp. 33-44. doi:10.1016/j.jneumeth.2003.12.024

[12] R. R. Noppens, J. Kofler, M. R. Grafe, P. D. Hurn and R. J. Traystman, "Estradiol after Cardiac Arrest and Cardiopulmonary Resuscitation Is Neuroprotective and Mediated through Estrogen Receptor- $\beta$," Journal of Cerebral Blood Flow \& Metabolism, Vol. 29, No. 2, 2009, pp. 277-286. doi:10.1038/jcbfm.2008.116

[13] A. Harkin, T. J. Connor, J. M. O’Donnell and J. P. Kelly, "Physiological and Behavioral Responses to Stress: What Does a Rat Find Stressful?” Lab Animal (NY), Vol. 31, No. 4, 2002, pp. 42-50.

[14] B. A. Rikke, J. E. Yerg, M. E. Battaglia, T. R. Nagy, D. B. Allison and T. E. Johnson, "Strain Variation in the Response of Body Temperature to Dietary Restriction," Mechanisms of Ageing and Development, Vol. 124, No. 5, 2003, pp. 663-678. doi:10.1016/S0047-6374(03)00003-4

[15] C. G. Tankersley, R. Irizarry, S. Flanders and R. Rabold, "Circadian Rhythm Variation in Activity, Body Temperature, and Heart Rate between $\mathrm{C} 3 \mathrm{H} / \mathrm{HeJ}$ and C57BL/6J Inbred Strains,” Journal of Applied Physiology, Vol. 92, No. 2, 2002, pp. 870-877.

[16] E. Kilic, U. Kilic, M. Bacigaluppi, et al., "Delayed Melatonin Administration Promotes Neuronal Survival, Neurogenesis and Motor Recovery, and Attenuates Hyperactivity and Anxiety after Mild Focal Cerebral Ischemia in Mice,” Journal of Pineal Research, Vol. 45, No. 2, 2008, pp. 142-148. doi:10.1111/j.1600-079X.2008.00568.x

[17] B. Winter, G. Juckel, I. Viktorov, et al., “Anxious and Hyperactive Phenotype Following Brief Ischemic Episodes in Mice,” Biological Psychiatry, Vol. 57, No. 10, 2005, pp. 1166-1175. doi:10.1016/j.biopsych.2005.02.010

[18] U. Ebmeyer, G. Keilhoff, G. Wolf and W. Röse, "Strain Specific Differences in a Cardio-Pulmonary Resuscitation Rat Model,” Resuscitation, Vol. 53, No. 2, 2002, pp. 189200. doi:10.1016/S0300-9572(02)00003-5

[19] F. Colbourne, H. Li and A. M. Buchan, "Indefatigable
CA1 Sector Neuroprotection with Mild Hypothermia Induced 6 Hours after Severe Forebrain Ischemia in Rats," Journal of Cerebral Blood Flow and Metabolism, Vol. 19, No. 7, 1999, pp. 742-749. doi:10.1097/00004647-199907000-00003

[20] C. Coimbra, F. Boris-Möller, M. Drake and T. Wieloch, "Diminished Neuronal Damage in the Rat Brain by Late Treatment with the Antipyretic Drug Dipyrone or Cooling Following Cerebral Ischemia," Acta Neuropathologica, Vol. 92, No. 5, 1996, pp. 447-453. doi:10.1007/s004010050545

[21] D. L. Clark, M. De Butte-Smith and F. Colbourne, "Spontaneous Temperature Changes in the 2-Vessel Occlusion Model of Cerebral Ischemia in Rats," Canadian Journal of Physiology Pharmacology, Vol. 85, No. 12, 2007, pp. 1263-1268. doi:10.1139/Y07-119

[22] S. J. Spencer, A. Mouihate and Q. J. Pittman, "Peripheral Inflammation Exacerbates Damage after Global Ischemia Independently of Temperature and Acute Brain Inflammation,” Stroke, Vol. 38, No. 5, 2007, pp. 1570-1577. doi:10.1161/STROKEAHA.106.476507

[23] D. W. Marion, Y. Leonov, M. Ginsberg, et al., "Resuscitative Hypothermia," Critical Care Medicine, Vol. 24, No. 2, 1996, pp. S81-S89. doi:10.1097/00003246-199602000-00050

[24] W. D. Dietrich, R. Busto, I. Valdes and Y. Loor, "Effects of Normothermic Versus Mild Hyperthermic Forebrain Ischemia in Rats,” Stroke, Vol. 21, No. 9, 1990, pp. 1318-1325. doi:10.1161/01.STR.21.9.1318

[25] R. W. Hickey, P. M. Kochanek, H. Ferimer, H. L. Alexander, R. H. Garman and S. H. Graham, "Induced Hyperthermia Exacerbates Neurologic Neuronal Histologic Damage after Asphyxial Cardiac Arrest in Rats," Critical Care Medicine, Vol. 31, No. 2, 2003, pp. 531-535. doi:10.1097/01.CCM.0000050323.84293.11

[26] O. Gavrilova, L. R. Leon, B. Marcus-Samuels, et al., "Torpor in Mice Is Induced by Both Leptindependent and Independent Mechanisms," Proceedings of the National Academy of Science of the USA, 7 December 1999, pp. 14623-14628. doi:10.1073/pnas.96.25.14623

[27] D. L. Clark, S. B. De Bow, M. D. Iseke and F. Colbourne, "Stress-Induced Fever after Postischemic Rectal Temperature Measurements in the Gerbil," Canadian Journal of Physiology and Pharmacology, Vol. 81, No. 9, 2003, pp. 880-883. doi:10.1139/y03-083

[28] S. DeBow and F. Colbourne, "Brain Temperature Measurement and Regulation in Awake and Freely Moving Rodents,” Methods, Vol. 30, No. 2, 2003, pp. 167-171. doi:10.1016/S1046-2023(03)00080-X

[29] D. Corbett, S. Evans, C. Thomas, D. Wang and R. A. Jonas, "MK-801 Reduced Cerebral Ischemic Injury by Inducing Hypothermia," Brain Research, Vol. 514, No. 2, 1990, pp. 300-304. doi:10.1016/0006-8993(90)91424-F

[30] S. Nurse and D. Corbett, "Neuroprotection after Several Days of Mild, Drug-Induced Hypothermia," Journal of Cerebral Blood Flow and Metabolism, Vol. 16, No. 3, 1996, pp. 474-480.

doi:10.1097/00004647-199605000-00014 
[31] H. Zhu, B. P. Meloni, S. R. Moore, B. T. Majda and N. W. Knuckey, "Intravenous Administration of Magnesium Is Only Neuroprotective Following Transient Global Ischemia When Present with Post-Ischemic Mild Hypothermia," Brain Research, Vol. 1014, No. 1-2, 2004, pp. 5360. doi:10.1016/j.brainres.2004.03.073

[32] F. Colbourne, G. R. Sutherland and R. N. Auer, "An Automated System for Regulating Brain Temperature in
Awake and Freely Moving Rodents," Journal of Neuroscience Methods, Vol. 67, No. 2, 1996, pp. 185-190. doi:10.1016/0165-0270(96)00047-7

[33] C. L. MacLellan, D. L. Clark, G. Silasi and F. Colbourne, "Use of Prolonged Hypothermia to Treat Ischemic and Hemorrhagic Stroke,” Journal of Neurotrauma, Vol. 26, No. 3, 2009, pp. 313-323. doi:10.1089/neu.2008.0580 